\title{
Coseismic response of groundwater level in the Three Gorges well network and its relationship to aquifer parameters
}

\author{
SHI ZheMing ${ }^{1,2}$, WANG GuangCai ${ }^{1,2,3^{*}}$, LIU ChengLong ${ }^{1,4}$, MEI JianChang ${ }^{5}$, WANG JinWei ${ }^{1} \&$ \\ FANG HuiNa ${ }^{1}$ \\ ${ }^{1}$ School of Water Resources and Environment, China University of Geosciences (Beijing), Beijing 100083, China; \\ ${ }^{2}$ MOE Key Laboratory of Groundwater Circulation and Environment Evolution, School of Water Resources and Environment, \\ China University of Geosciences (Beijing), Beijing 100083, China; \\ ${ }^{3}$ State Key Laboratory of Biogeology and Environmental Geology, China University of Geosciences (Beijing), Beijing 100083, China; \\ ${ }^{4}$ Institute of Geology, China Earthquake Administration, Beijing 100029, China; \\ ${ }^{5}$ Earthquake Administration of Hubei Province, Wuhan 430071, China
}

Received December 6, 2012; accepted April 3, 2013; published online June 4, 2013

The 12 May 2008 Ms 8.0 Wenchuan earthquake caused notable changes in the water levels of wells in the Three Gorges area. This work examines the relationship between these coseismic changes in water level and the changes in aquifer parameters. Three wells in the area with good responses to earth tide were chosen for analysis. Water-level data from February to June 2008 were used to calculate the aquifer transmissivity, permeability and specific storage of the rocks, and analyze the relationship between the coseismic responses of the wells and their aquifer parameters. The results show that the Wenchuan earthquake changed these parameters considerably, thereby controlling co- and postseismic variations of water level. The values of these parameters prior to the earthquake are linearly related with the amplitudes of coseismic variations in water level. The larger the aquifer transmissivity, the more remarkable the coseismic change in water level. During the earthquake, changes in aquifer parameters were found to be associated with coseismic variations in water level, with the larger changes occurring when the coseismic variation in water level was larger. The tectonic setting has a certain degree of influence on the co- and postseismic changes in water level. The permeability structures of the fault zone appear to determine the manner of coseismic variation in water level. Moreover, it seems that the water level in wells where groundwater converges more easily can recover faster following an earthquake. Insight from this study helps to improve understanding of the characteristics of water-level changes caused by earthquakes.

Wenchuan earthquake, Three Gorges well network, groundwater level, tidal effect, aquifer parameter

Citation: Shi Z M, Wang G C, Liu C L, et al. Coseismic response of groundwater level in the Three Gorges well network and its relationship to aquifer parameters. Chin Sci Bull, 2013, 58: 3080-3087, doi: 10.1007/s11434-013-5910-3

A great number of observations and studies demonstrate that earthquakes can induce various hydrogeological phenomena, including, most notably, changes in groundwater level [1-7]. Such changes can include step-changes in water level, water-level oscillations, and sustained change in water level [8-11]. Usually, a step-change in water level is considered to be caused by static stress release as fault slips [12-15]. Seismic waves can also lead to step-changes [10] and oscillations [2,16-18] in groundwater level. Sustained

*Corresponding author (email: wanggc@pku.edu.cn) change in water level has been linked to variation in aquifer permeability as a result of seismic waves [8,10,19]. Earthquakes can modify the structure of an aquifer, thereby changing aquifer parameters and ongoing coseismic variations in water level [5,11,19-22]. Furthermore, the ways in which water level recovers after a seismic event are associated with aquifer parameters [4,8,23]. Because seismic wave propagation through an aquifer is a dynamic process, the relationships between seismic amplitude, coseismic variation in water level and post-seismic water level recovery need to be studied further. 
The 12 May 2008 Ms 8.0 Wenchuan earthquake caused notable coseismic changes in water level in the wells of the Three Gorges area. This paper is based on observational data from the Three Gorges groundwater network. Using water-level changes from three wells, we have estimated aquifer parameters on the basis of water-level response to earth tides, and have analyzed the relationship between the changed aquifer parameters and variations of water level associated with the earthquake.

\section{The observational wells and their responses to the earthquake}

\subsection{Geological setting}

The three wells studied in this paper, Dinjiaping (DJP), Maoping (MP), and Guojiaba (GJB), are part of the Three Gorges groundwater observational network, established to investigate reservoir-induced seismicity in the vicinity of the Three Gorges Dam [24]. The DJP and MP wells lie on the southern and northern sides of the dam, respectively, and the GJB well is located in the headwater area of the reservoir (Figure 1). All three are situated near the junctions or ends of faults (Figure 1, Table 1). The three wells were constructed in 2001, and long-term observations since then show good responses to earth tides. As they penetrate confined aquifers, these three wells are sensitive to the response of crustal strain in these water-bearing units [25,26].

The DJP well lies on the western side of a small gully in the hilly northern bank of the Yangtze River where there are intrusions of biotite-bearing quartz diorite. Nearby, the SSE-NNW trending Gaojiachong Fault comes very close to meeting the SSW-NNE trending Changmutuo Fault, without actually intersecting it. The well is $100 \mathrm{~m}$ west of the Gaojiachong Fault, which dips $\mathrm{NE}$ at $60^{\circ}-80^{\circ}$, extending over a length of $16 \mathrm{~km}$ and width of $16-23 \mathrm{~m}$. The fault is reverse with a shear component, and has been active over many epochs as a major discontinuity in the crystalline

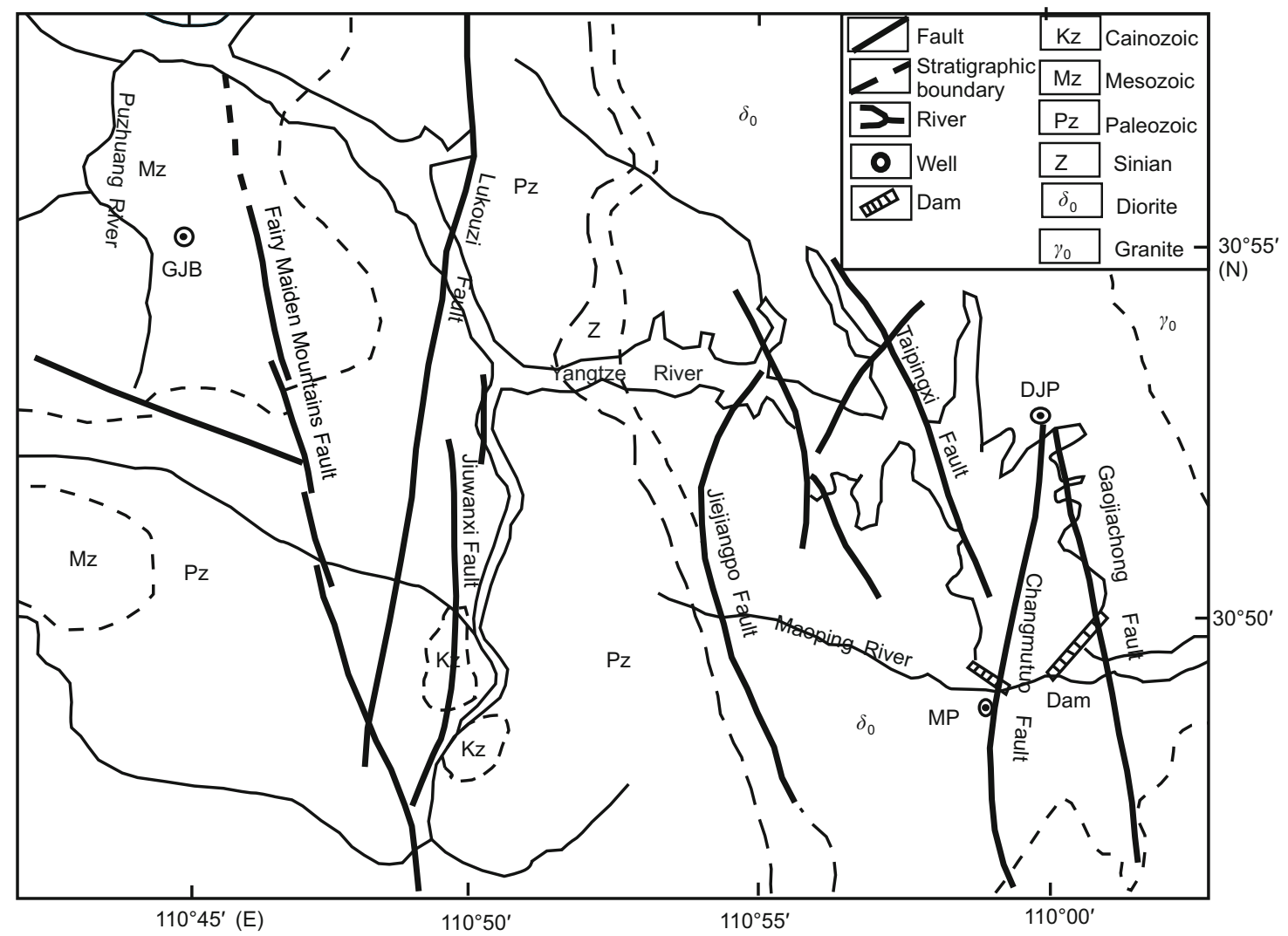

Figure 1 Sketch map showing geology of the Three Gorges area and locations of the three wells (DJP, MP, GJB).

Table 1 Basic data of the three wells

\begin{tabular}{|c|c|c|c|c|c|c|}
\hline Well name & Depth (m) & $\begin{array}{c}\text { Casing length } \\
(\mathrm{m})\end{array}$ & $\begin{array}{c}\text { Diameter } \\
\text { of well }(\mathrm{m})\end{array}$ & $\begin{array}{c}\text { Diameter } \\
\text { of bare hole }(\mathrm{m})\end{array}$ & $\begin{array}{c}\text { Aquifer } \\
\text { lithology }\end{array}$ & Tectonic setting \\
\hline DJP & 153.1 & 80 & 0.133 & 0.114 & quartz diorite & junction of Changmutuo and Gaojiachong faults \\
\hline MP & 200.5 & 80 & 0.133 & 0.114 & quartz diorite & hanging wall of Changmutuo and Fault \\
\hline GJB & 200.3 & 100 & 0.133 & 0.114 & sandy shale & end of Fairy Maiden Mountains Fault, syncline flank \\
\hline
\end{tabular}


basement rock. The fault is relatively straight and well cemented, with well-developed tectonite and continuous mylonite and cataclastic rock on either side. Not much breccia is observed, but phyllonite and scattered occurrences of mudstone are present at individual locations.

The MP well is situated on the south side of the Yangtze River, east of the Maoping River and bed-rock hills in the east, where intrusions of biotite-bearing quartz diorite are present. The well is $50 \mathrm{~m}$ west of the central section of the Changmutuo Fault. The fault's trajectory varies along its length; the southern section strikes NNW-SSE, the middle is N-S, and the northern section in NNE-SSW. The fault dips NW at $70^{\circ}-83^{\circ}$ over a length of $10 \mathrm{~km}$ and with a width of $20-25 \mathrm{~m}$. It is an extensional fracture zone with a shear slip component, and locally has 0.5-1-m-wide mylonite zone and a 5-15-m-thick breccia. The fault is also in a well-cemented state.

The GJB well is on the eastern side of a mountain valley, in the hilly region west of the Puzhuang River. Triassic carbonatite and Jurassic sandy shale are the dominant units here, forming a syncline. The well is on the flank of the syncline, in the hanging wall of the Fairy Maiden Mountains
Fault. With the growth of extensional sub-faults and distribution of the poorly cemented cataclastic rock, the fault favors infiltration of surface water. This causes the fault to act as a groundwater conduit, producing springs that are distributed along the fault. The fault probably formed after the Cretaceous as a predominantly strike-slip fault, which has now become extensional with a shear component [27].

Digital instruments (DSW-01) developed by the Institute of Seismology, China Earthquake Administration were installed in these three wells for measurements of water level. The accuracy and sampling rate are $1 \mathrm{~mm}$ and $1 \mathrm{~min}$ [28].

\subsection{Responses of the three wells to the Wenchuan earthquake}

During the 12 May 2008 Ms8.0 Wenchuan earthquake, eight wells in the Three Gorges network recorded coseismic responses of water level. The hydrographs of the three wells reported here are displayed in Figure 2.

As shown in Figure 2, the water levels in the three wells changed immediately following the Wenchuan earthquake. In the DJB and MP wells, the water level fell abruptly and
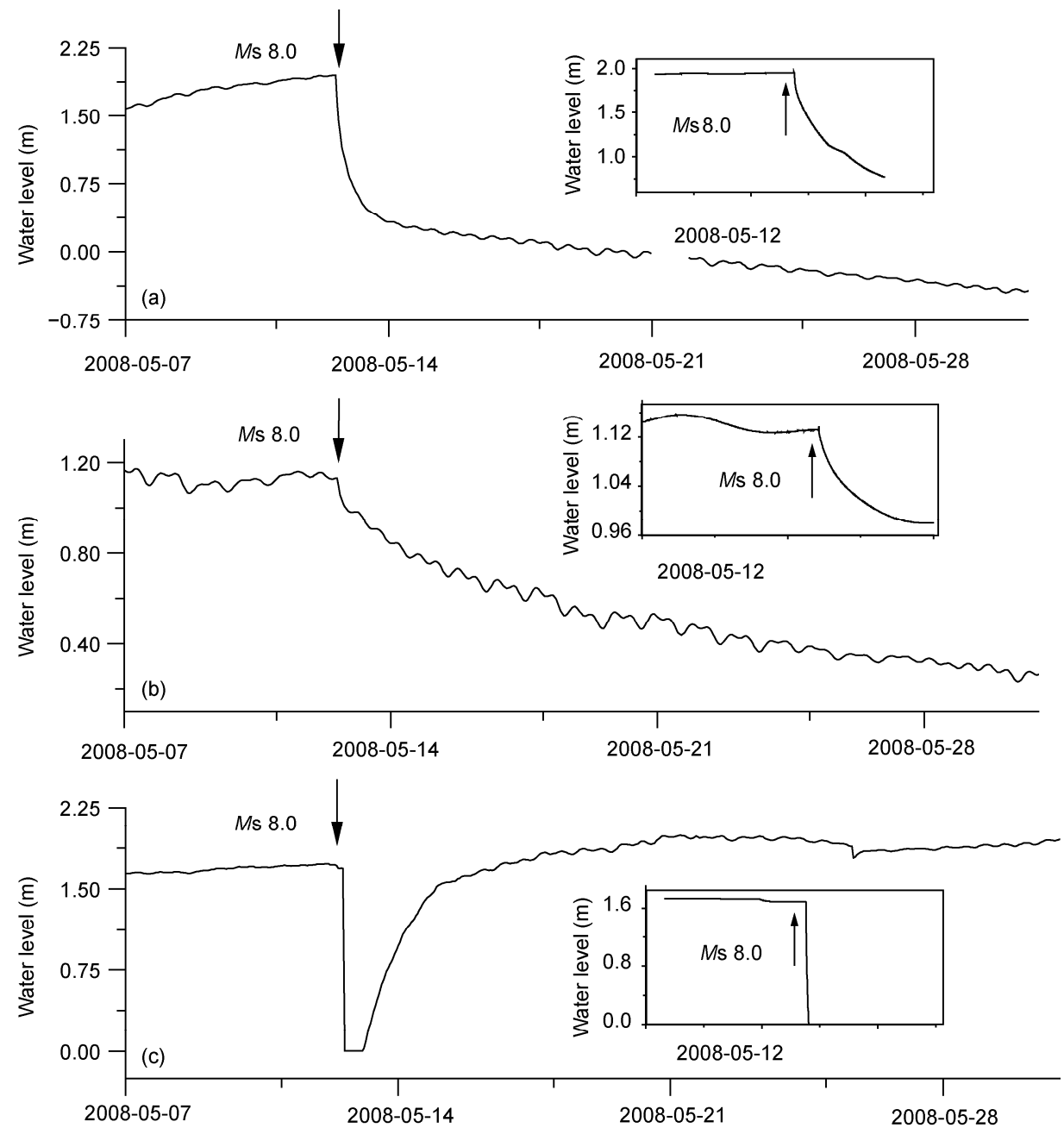

Figure 2 Coseismic responses of water level in (a) DJP, (b) MP and (c) GJB. The curves in the small frames show the water-level changes on 12 May, 2008. 
then continued to drop for a period more than 15 days when it recovered to the state prior to the event. In the GJB well, the response is characterized by a step-decline, and then the water level returned to normal about 3 days after the main shock.

Remarkable differences are also seen in the amplitude of the water level changes in the three wells: $122 \mathrm{~cm}$ for DJB, $17.8 \mathrm{~cm}$ for MP, and $172 \mathrm{~cm}$ for GJB. This may be related to the hydrogeological setting. GJB is located in a carbonatite and sandy shale aquifer, whereas DJP and MP are both located in a diorite aquifer. In general, the transmissivity of the sandy shale aquifer is much greater than that of the diorite aquifer. Also, the faults near DJP and MP are both in well-cemented states, which could contribute to the smaller transmissivity. The poorly cemented Fairy Maiden Mountain Fault would have the opposite effect.

To investigate possible explanations for the linkages between coseismic changes in water level and aquifer properties, we estimate aquifer parameters based on an inversion of water-level responses to earth tides and study their influences on water-level changes and other aquifer features, as described below.

\section{Calculation of aquifer parameters before and after an earthquake}

Periodic changes in water level are known to occur in confined aquifers in response to earth tides $[13,29]$. The amplitude of these changes depends on the compression coefficient and Poisson's ratio of the aquifer, as well as the compression coefficient of the water. However, the phase lag between the tidal dilatation of the aquifer and the water-level response in a well is primarily influenced by the transmissivity and storage coefficient of the aquifer [5]. Therefore, aquifer parameters such as the specific storage and transmissivity can be derived from the response of groundwater level to earth tides [29-33]. Furthermore, changes in aquifer permeability as the result of an earthquake can be calculated by comparative analyses of the tidal response of water levels before and after the earthquake [21]. To do this, the tidal factor and water-level phase lag must be determined. The tidal factor, which is also called strain sensitivity, is the ratio between the measured amplitude of water-level changes and the amplitude of the earth tide. We used the water-level data collected from February to June 2008 for the three wells. Baytap-G software was employed to analyze the tidal effects. The program uses Akaike's Bayesian information criterion. It supposes that a time series can be divided into the following parts [34]:

$$
y_{i}=\sum_{m=1}^{M}\left(\alpha_{m} C_{m i}+\beta_{m} S_{m i}\right)+\sum_{k=0}^{K} b_{k} x_{i-k}+d_{i}+e_{i} .
$$

The first term on the right-hand side is the tidal component: $C_{m i}$ and $S_{m i}$ are theoretically calculated values for an $m$ th group of tidal constituents, and $\alpha_{m}$ and $\beta_{m}$ are tidal response constants that are determined in the statistical model. The barometric response component is expressed as $\sum_{k=0}^{K} b_{k} x_{i-k}$, where $x_{i-k}$ is the observed barometric pressure and $b_{k}$ is a response coefficient, $d_{i}$ is the long-term trend, and $e_{i}$ is the noise.

In the analysis, we take a time interval of $10 \mathrm{~d}$ and then use a 5-d slide step-length to extract water-level parameters such as the phase lag, tidal factor and amplitude of the tides.

The earth tides considered in this study include $O_{1}, K_{1}$, $M_{2}$, and $S_{2}$ sub-waves, which account for at least $95 \%$ of all tidal waves [35]. Among the major sub-waves, $M_{2}$ and $O_{1}$ waves are relatively stable, and are uninfluenced by barometric pressure. The amplitude of $M_{2}$ is larger than that of $O_{1}$, and the least affected by barometric pressure [36]. Therefore, we chose the tidal sub-wave $M_{2}$ for analysis. Figures 3 and 4 show the temporal variation in tidal factors and phase lags of the $M_{2}$ wave in the three wells.

As shown in Figure 3, the tidal factors of the three wells experienced little change in amplitude from 1 February to 30 April 2008. When the Wenchuan earthquake occurred on 12 May 2008, these factors increased suddenly and did not recover in the month following the event. Phenomena similar to those in the amplitude information appeared in the phase lags, except they seemed to recover gradually by a month after the earthquake, although not to the levels prior to the main shock.

A relationship exists between the tidal factor and specific storage as follows [29,31]:
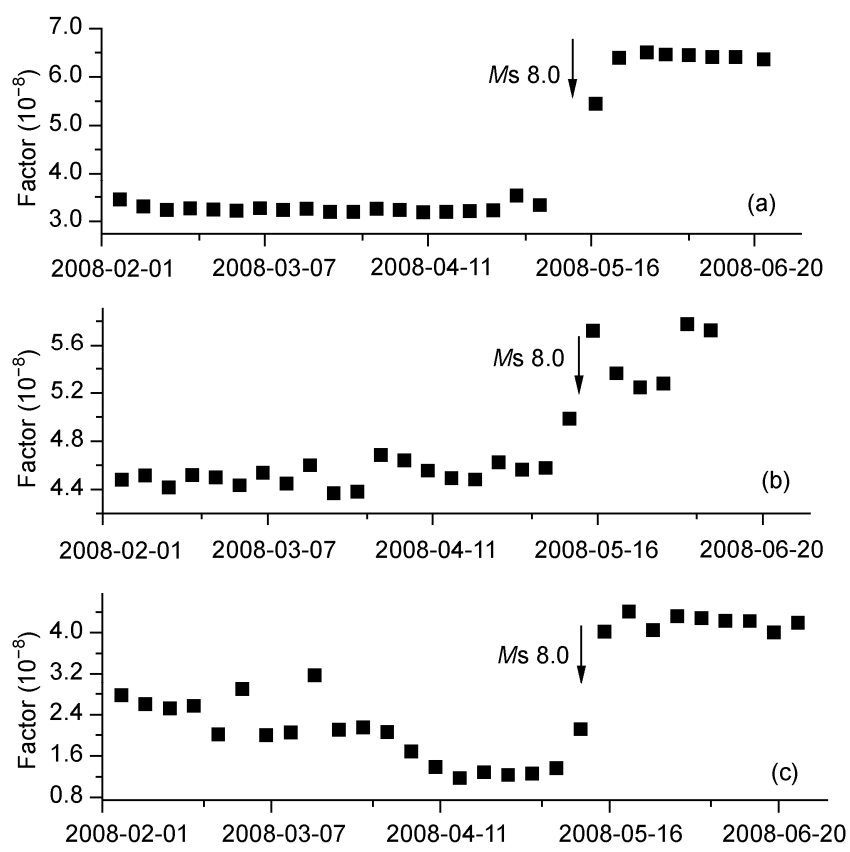

Figure 3 Tidal factors varying with time in (a) DJP, (b) MP and (c) GJB. 

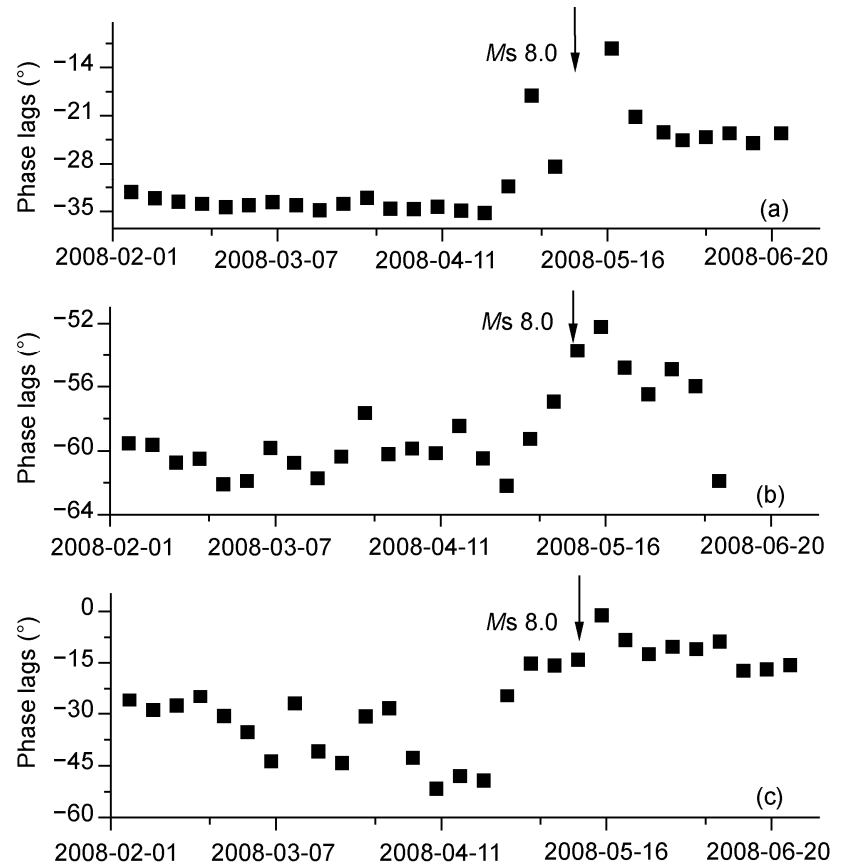

Figure 4 Phase lags varying with time in (a) DJP, (b) MP and (c) GJB.

$$
\frac{\Delta h}{\varepsilon_{t}}=-\frac{1}{S_{s}},
$$

where $\Delta h$ is the water-level change, $\mathrm{m} ; \varepsilon_{t}$ is the volumetric strain of the aquifer, and $S_{s}$ is specific storage, $1 / \mathrm{m}$. When the ratio of the water-level change to the volumetric strain of an aquifer is known, the specific storage of the aquifer can be determined. Here the ratio is also called the tidal factor, which can be derived directly from tidal analysis.

The transmissivity can be calculated from a tide analysis of phase lag $[21,30]$ :

$$
\begin{gathered}
A=\left(E^{2}+F^{2}\right)^{-\frac{1}{2}}, \\
\eta=-\tan ^{-1}(F / E),
\end{gathered}
$$

where

$$
E \approx 1-\frac{\omega r_{\mathrm{c}}^{2}}{2 T} \operatorname{Kei}(\alpha), \quad F \approx \frac{\omega r_{\mathrm{c}}^{2}}{2 T} \operatorname{Ker}(\alpha), \quad \alpha_{\mathrm{w}}=\left(\frac{\omega S}{T}\right)^{\frac{1}{2}} r_{\mathrm{w}},
$$

where $A$ and $\eta$ are the amplitude and phase responses; $T$ is the transmissivity, $\mathrm{m}^{2} / \mathrm{d} ; S$ is storage coefficient, Ker and $K e i$ are zero-order Kelvin functions, $r_{\mathrm{w}}$ is the unscreened open well radius, $r_{\mathrm{c}}$ is the casing radius of the well, and $\omega$ is tidal frequency, $1 / \mathrm{s}$.

Using eqs. (2)-(5) and tidal analysis, we obtained variations in the specific storage and transmissivity of the aquifers near the three wells with time (Figures 5 and 6).

In Figure 5, before the Wenchuan earthquake, the specific storage of the DJP well remained at about $3 \times 10^{-5}(1 / \mathrm{m})$.

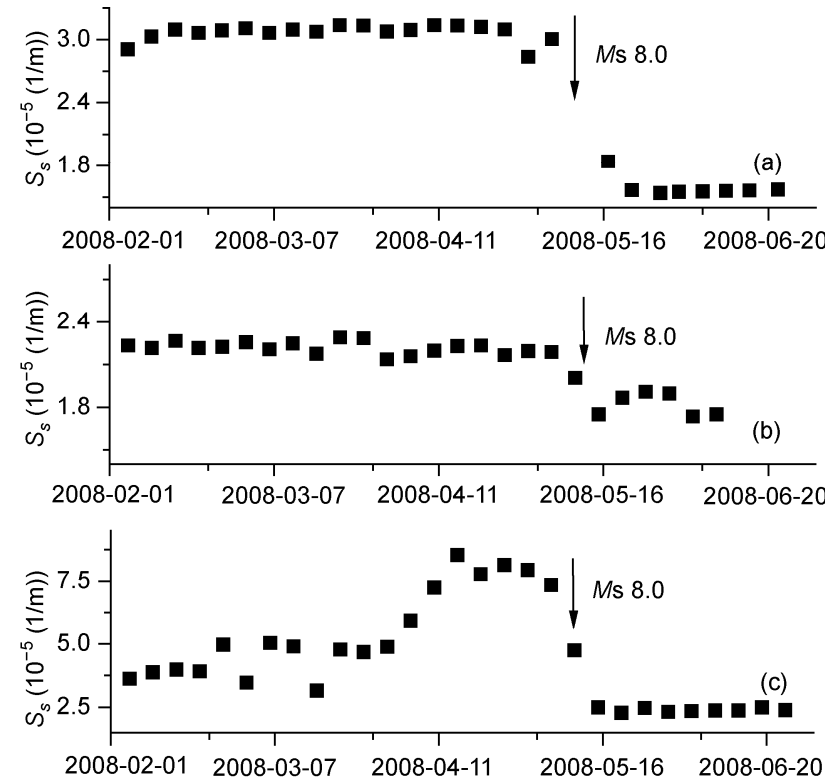

Figure 5 Specific storage versus time in (a) DJP, (b) MP and (c) GJB.
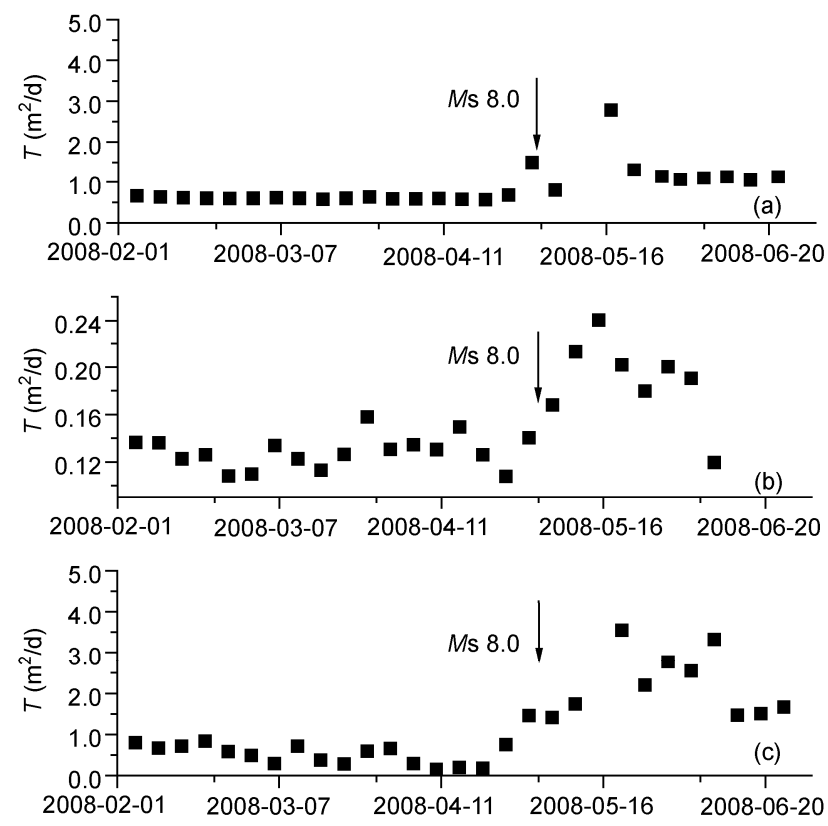

Figure 6 Transmissivity versus time in (a) DJP, (b) MP and (c) GJB.

After the quake, it dropped rapidly to $1.5 \times 10^{-5}(1 / \mathrm{m})$, implying a change in the amplitude ratio of $50 \%$. At well MP, these three values are $2.1 \times 10^{-5}(1 / \mathrm{m}), 1.7 \times 10^{-5}(1 / \mathrm{m})$ and $20 \%$, respectively. At well GJB, the specific storage was $4 \times 10^{-5}(1 / \mathrm{m}) 2$ months prior to the Wenchuan event, then increased gradually to $7.5 \times 10^{-5}(1 / \mathrm{m})$ immediately before the shock, and declined to $2.5 \times 10^{-5}(1 / \mathrm{m})$ after the quake, indicative of a change ratio of $66 \%$.

Transmissivity values were $0.7,0.14$, and $1.4 \mathrm{~m}^{2} / \mathrm{d}$ before the Wenchuan event at wells DJP, MP and GJB, respectively. After the earthquake, they increased to $1.4,0.24$, and $3.5 \mathrm{~m}^{2} / \mathrm{d}$, showing change ratios of $100 \%$ for DJP, $70 \%$ for 
MP and $150 \%$ for GJB (Figure 6). The coseismic response in specific storage and transmissivity operate in opposite directions. If an earthquake makes a specific storage coefficient smaller, transmissivity becomes larger.

\section{Relationship between co- and postseismic water-level responses and aquifer parameters}

The water levels in the three wells expressed different coand postseismic responses as a result of the Wenchuan earthquake. These three wells are in a similar geologic setting and are in close proximity within an area that is roughly $20 \mathrm{~km}$ from east to west and $15 \mathrm{~km}$ from north to south [9]. What, then, are the factors that caused their responses to the earthquake to be different? Here we consider the possible influence of tectonic setting and aquifer parameters to explain the groundwater response observed at these wells.

As illustrated in Figure 2, both the wells DJP and MP, with a slow postseismic decrease in water level, lie near the NNE-SSW trending Changmutuo Fault, whereas well GJB, with its step drop-recover pattern, is situated close to the NNW-SSE striking Fairy Maiden Mountains Fault.

As for the coseismic change in the water-level amplitude, DJP was $122 \mathrm{~cm}$, MP was $17.8 \mathrm{~cm}$, and GJB was $172 \mathrm{~cm}$. Comparison of these values with transmissivity estimated from earth tides indicates a good linear relation between coseismic changes in water level and aquifer parameters (Figure 7).
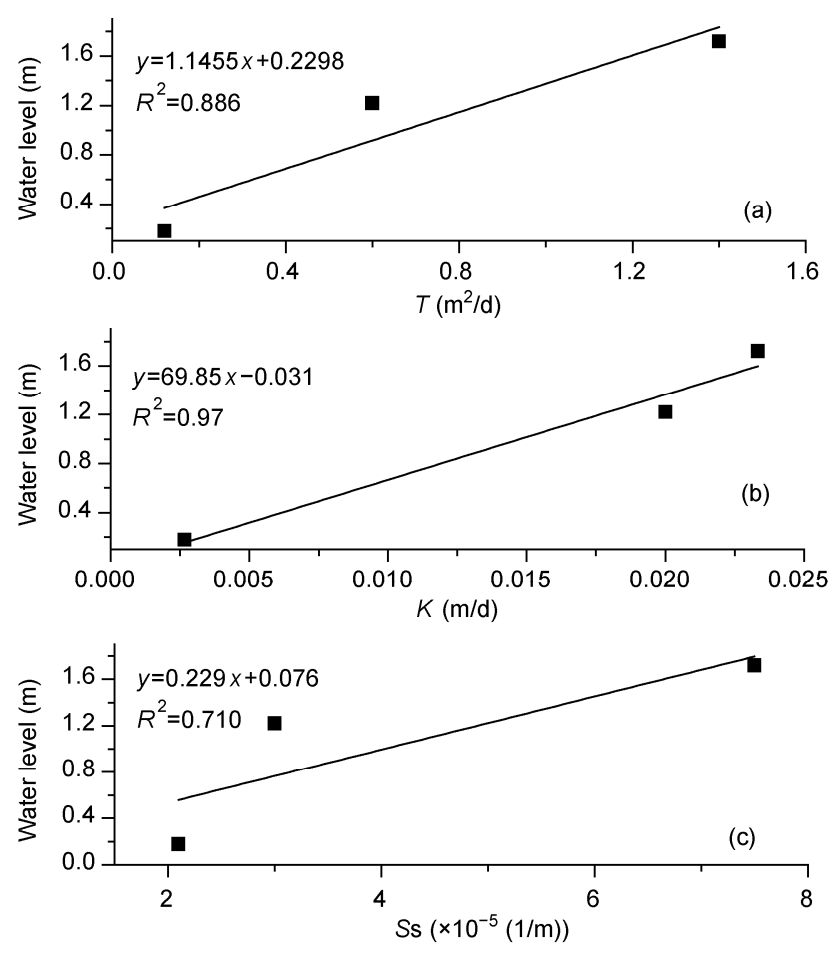

Figure 7 Coseismic changes in the amplitude of water level versus aquifer parameters. (a) Transmissivity; (b) permeability; (c) specific storage.
From Figure 7, coseismic changes in the amplitude of water levels are most linearly correlated with permeability, next is transmissivity, and specific storage is last. In general, specific storage primarily depends on the degree of compression and the porosity of an aquifer framework. A likely reason for the change of aquifer permeability as a result of the dynamic stress of seismic waves is the removal of sediments from pores, whereas the whole framework of the aquifer does not change significantly [10]. Consequently, coseismic changes in water level are relatively weakly related to specific storage. On the other hand, transmissivity and permeability represent the ability of an aquifer to transmit fluids. When seismic waves promote the removal of sediments from pores, water on the up- or downgradient side will exchange with the water in a well, resulting in a change of the water level in the well. Thus, transmissivity has a larger effect on coseismic changes in water level. As transmissivity increases, this coseismic change in amplitude also increases, because more water is exchanged between the well and surrounding aquifers. Besides, as previously calculated, the change ratios for transmissivity as a result of the earthquake are $150 \%$ for GJB, $100 \%$ for DJP, and $70 \%$ for MP. Also, the change ratios of specific storage as a result of the earthquake are $66 \%$ for GJB, $50 \%$ for DJP, and $20 \%$ for MP. Note that the larger the change in aquifer parameter, the larger the coseismic change in water levels becomes.

As for the post-earthquake recovery of water levels, well GJB returned to its pre-earthquake value in $72 \mathrm{~h}$, whereas the times for DJP and MP for such recovery are much longer. The reason for this difference is probably related to the varied aquifer permeability in the wells. After the Wenchuan earthquake, the aquifer permeability of GJB was relatively high, while that of DJP and MP was low. When the surrounding aquifers have high permeability, water exchange is facilitated between the well and aquifers. thus, post-earthquake recovery of water level is faster. In addition, the tectonic setting of the wells also influences the process of water-level recovery. Well GJB, located on the flank of a syncline, is well positioned to favor groundwater confluence, and the nearby Fairy Maiden Mountains Fault likely contains much water. This means that GJB likely receives more of a water supply from its surroundings than DJP and MP do, so its water level resumed to the pre-earthquake value more quickly. In contrast, the aquifers of DJP and MP have relatively low permeability, and the nearby fault bears not much water. Therefore, the post-earthquake recovery of water level was much slower at both of these wells.

\section{Conclusions}

This work has been based on data from three wells in the Three Gorges area. Our purpose was to analyze the characteristics of co- and postseismic variations in water level 
associated with the $2008 \mathrm{Ms} 8.0$ Wenchuan earthquake and their relationships with aquifer parameters. The following conclusions can be drawn.

(1) Water-level data from the three wells from 1 February to 30 June 2008 have revealed temporal variations in the specific storage, transmissivity and permeability. The results show that when the Wenchuan earthquake occurred, the specific storage of the three wells dropped $66 \%$ for GJB, $50 \%$ for DJP, and $20 \%$ for MP, while their transmissivities increased $150 \%$ for GJB, $100 \%$ for DJP and $70 \%$ for MP.

(2) Variations in coseismic water level are closely associated with aquifer parameters. The amplitude of coseismic change is linearly related to aquifer transmissivity and specific storage prior to the earthquake, especially the former, which exerts a dominant role. A larger change in aquifer parameter corresponds to a larger coseismic change in water level.

(3) The tectonic and hydrogeological settings of wells can somewhat influence coseismic changes and postseismic recovery of water level. Coseismic changes in water level in wells located on the same fault exhibit consistent trends. Wells located in a sediment aquifer with a poorly cemented fault have a greater coseismic water level response than what would be observed in a diorite aquifer with a well-cemented fault nearby.

(4) In general, greater transmissivity allows water levels to recover more quickly after a seismic event. With greater aquifer transmissivity, the water in a well can be more easily exchanged with the aquifer. Thus, its water level recovers rapidly after an earthquake.

In summary, co- and postseismic changes in well water levels depend on the geological setting, aquifer water content, and aquifer parameters of the rock. A well's tectonic setting and other factors can also influence coseismic variations of water level in the well.

The authors thank three reviewers for their insightful comments and the editor for kind help that considerably improved the quality of the manuscript. This work was supported by the National Natural Science Foundation of China (40930637), the Special Project for Earthquake Science (200808079), the Specialized Research Fund for the Doctoral Program of Higher Education of China (20100022110001), and a Special Project of the Seismological Community (IGCEA-1205).

1 Rexin E E, Oliver J, Prentiss D. Seismically-induced fluctuations of the water level in the Nunn-Bush well in Milwaukee. Bull Seismol Soc Am, 1962, 52: 17-25

2 Cooper H H, Bredhoeft J D, Papadoup I S, et al. The response of well-aquifer system to seismic waves. J Geophys Res, 1965, 70: 3915-3926

3 Igarashi G, Wakita H, Sato H. Precursory and coseismic anomalies in well water levels observed for the Frebruary 2, 1992 Tokyo Bay earthquake. Geophys Res Lett, 1992, 19: 1583-1586

4 Roeloffs E A, Sneed M, Galloway D L, et al. Water-level changes induced by local and distant earthquakes at Long Valley caldera, California. J Volcanol Geotherm Res, 2003, 127: 269-303

5 Matsumoto N, Roeloffs E A. Hydrological response to earthquakes in the Haibara well, central Japan-II. Possible mechanism inferred from time-varying hydraulic properties. Geophys J Int, 2003, 155: 899913

6 Manga M, Wang C Y. Earthquake hydrology. In: Schubert G, ed. Treatise on Geophysics. Amsterdam: Elsevier, 2007. 293-320

7 Wang C Y, Chia Y. Mechanism of water level changes during earthquakes: Near field versus intermediate field. Geophys Res Lett, 2008, 35: L12402

8 Roeloffs E A. Persistent water level changes in a well near Parkfield, California, due to local and distant earthquakes. J Geophys Res, 1998, 103: 868-889

9 Liu C L, Wang G C, Zhang W H, et al. Co-seismic response of well water level in the Three Gorges well-network to the $M$ s 8.0 earthquake in Wenchuan (in Chinese). Acta Seismol Sin, 2009, 31: 188194

10 Brodsky E E, Roeloffs E A, Woodcock D, et al. A mechanism for sustained groundwater pressure changes induced by distant earthquakes. J Geophys Res, 2003, 108: 2390

11 Wang G C, Shen Z L. Seismic groundwater monitoring and earthquake prediction (in Chinese). Chin J Nat, 2010, 32: 90-93

12 Wakita $\mathrm{H}$. Water wells as possible indicators of tectonic strain. Science, 1975, 189: 553

13 Roeloffs E A. Poroelastic techniques in the study of earthquake related hydrologic phenomena. Adv Geophys, 1996, 37: 135-195

14 Ge S, Stover S C. Hydrodynamic response to strike and dip-slip faulting on a half-space. J Geophys Res, 2000, 105: 25513-25524

15 Jónsson S, Segall P, Pedersen R. Post-earthquake ground movements correlated to pore pressure transients. Nature, 2003, 424: 179-183

16 Kano Y, Yanagidani T. Broadband hydroseismograms observed by closed borehole wells in the Kamioka mine, central Japan: Response of pore pressure to seismic waves from 0.05 to $2 \mathrm{~Hz}$. J Geophys Res, 2006, 111: B03410

17 Liu L B, Roeloffs E, Zheng X Y. Seismically induced water level fluctuations in the Wali well, Beijing, China. J Geophys Res, 1989, 94: 9453-9462

18 Zhang Z D, Chi Z L, Chen H M, et al. The transmissibility coefficient of well aquifers and its response to seismic waves (in Chinese). Inland Earthq, 1999, 13: 207-214

19 Rojstaczer S, Wolf S, Michel R. Permeability enhancement in the shallow crust as a cause of earthquake-induced hydrological changes. Nature, 1995, 373: 237-239

20 Charmoille A, Fabbri O, Mudry J. Post-seismic permeability change in a shallow fractured aquifer following a $M_{\mathrm{L}} 5.1$ earthquake (Fourbanne karst aquifer, Jura outermost thrust unit, eastern France). Geophys Res Lett, 2005, 32: L18406

21 Elkhoury J E, Brodsky E E, Agnew D C. Seismic waves increase permeability. Nature, 2006, 441: 1135-1138

22 Wang C Y, Chia Y, Wang P L, et al. Role of S waves and Love waves in coseismic permeability enhancement. Geophys Res Lett, 2009, 36: L09404

23 Gavrilenko P, Melikadze G, Chelidze T. Permanent water level drop associated with the Spitak earthquake: Observations at Lisi borehole (Republic of Georgia) and modelling. Geophys J Int, 2000, 143: 8398

24 Che Y T, Yu J Z, Liu W Z, et al. Arrangement of well network and establishment of observation wells at Three Gorges of the Yangtze River (in Chinese). Seismol Geol, 2002, 24: 423-431

25 Liu W Z, Yu J Z, Che Y T, et al. Behaviors of subsurface fluid and their responsibility to seismic event in Three Gorges observation well network (in Chinese). Seismol Geol, 2003, 25: 632-646

26 Che Y T, Liu W Z, Yan P, et al. Subsurface fluid behaviors and its changes in three Gorges well network before and after reservoir impounding (in Chinese). J Geod Geodyn, 2004, 24: 14-22

27 Che Y T, Chen J H, Zhang L F, et al. Study of reservoir-induced Hujiaping Ms 4.1 earthquakes in the Three Gorges dam area (in Chinese). Earthquake, 2009, 29: 423-431

28 Li J M, Yao Y S, Mei J C, et al. Application of DSW-01 water level meter to observational well network in Three Gorges (in Chinese). J Geod Geodyn, 2006, 26: 121-125 
29 Bredehoeft J D. Response of well-aquifer systems to earth tides. J Geophys Res, 1967, 72: 3075-3087

30 Hsieh P A, Bredehoeft J D, Farr J M. Determination of aquifer transmissivity from earth tide analysis. Water Resour Res, 1987, 23: 1824-1832

31 Hsieh P A, Bredehoeft J D, Rojstaczer S. Response of well system to earth tides: Problem revisited. J Geophys Res, 1988, 24: 468-472

32 Merritt M L. Estimating hydraulic properties of the Floridan aquifer system by analysis of earth-tide, ocean-tide, and barometric effects,
Collier and Hendry Counties, Florida. USGS Report. 2004

33 Cutillo P A, Bredehoeft J D. Estimating aquifer properties from the water level response to earth tides. Ground Water, 2011, 49: 600-610

34 Tamura Y, Sato T, Ooe M, et al. A procedure for tidal analysis with a Bayesian information criterion. Geophys J Int, 1991, 104: 507-516

35 Wang C M, Che Y T, Wan D K, et al. Study of Micro-behavior of Gorundwater (in Chinese). Beijing: Seismological Press, 1988. 10-16

36 Doan M L, Brodsky E E, Prioul R, et al. Tidal analysis of borehole pressure: A tutorial. Research Report, 2006

Open Access This article is distributed under the terms of the Creative Commons Attribution License which permits any use, distribution, and reproduction in any medium, provided the original author(s) and source are credited. 